Thorax (1970), 25, 19.

\title{
Fever in aspergillus mycetoma
}

\author{
C. HILVERING, E.A. M. STEVENS, N. G. M. ORIE \\ University Hospital, Groningen, The Netherlands
}

\begin{abstract}
Two patients with aspergillus mycetoma presenting with fever as a major sign are described. The clinical presentation is correlated with the results of experimental inhalation of Aspergillus fumigatus extract in patients with aspergillus mycetoma. A theory is put forward which tries to explain fever and haemoptysis as belonging to a type III (Gell and Coombs, 1963) antigenantibody reaction. Therapeutic implications are discussed.
\end{abstract}

Fever as a sign of growth of Aspergillus fumigatus in the lungs is known only in patients with allergic aspergillosis (Hinson, Moon, and Plummer, 1952 ; Pepys, Riddell, Citron, Clayton, and Short, 1959) and acute pulmonary aspergillosis (Hertzog, Smith, and Goblin, 1949 ; Delikat and Dyke, 1945 ; Strelling, Rhaney, Simmons, and Thomson, 1966). Fever and malaise as major signs in patients with aspergillus mycetoma have up till now been described only by Dieulafoy (1920).

Here we describe two patients with aspergillus mycetoma in the lung, presenting with fever and malaise as major signs, and suggest that the fever is the result of an aspergillus antigen-antibody reaction. We base this view on the results of inhalation tests in patients with aspergillus mycetoma, presented by Stevens, Hilvering, and Orie, in a preceding paper in this issue (p. 11).

\section{CASE REPORTS}

PATIENT 1 This 44-year-old housewife had scleroderma, poikiloderma, bilateral cataract, and slowly progressive neurological symptoms that have ultimately led to a Brown-Séquard syndrome. A diagnosis of Werner's syndrome (Annotation, 1967) has been considered. Probably secondary to fibrosis, an aspergillus mycetoma developed in the left lung, as was shown by radiographs (Fig. 1) and by the presence of precipitating antibodies in the serum (Fig. 2).

During the first admission (13 April to 27 May 1966) her body temperature was subfebrile and the E.S.R. was $20 \mathrm{~mm}$. after one hour. Only sporadically was some haemorrhagic sputum produced. A month after discharge her condition worsened, and she started coughing, producing large amounts of purulent, haemorrhagic sputum. When she was admitted for the second time the patient appeared to be ill, she had lost about $8 \mathrm{~kg}$., the body temperature was febrile -between $38^{\circ}$ and $40^{\circ}$ C.- and the E.S.R. had risen to $85 \mathrm{~mm}$. On radiographic examination the mycetoma had increased in size (Fig. 3). A. fumigatus could now be cultured from the sputum. Other micro-organisms could not be demonstrated in blood, sputum, or urine. A course of amphotericin B was started but had to be stopped because of acute renal insufficiency. Eventually we decided to remove her left lung. Treatment with prednisolone, $25 \mathrm{mg}$. daily, was started a week before the operation. This caused a remarkable improvement in her condition, and the body temperature became normal. A left pneumonectomy was performed on 14 December 1966. During the procedure the wall of the mycetoma ruptured, resulting in spilling of its contents into the pleural cavity. Postoperatively, amphotericin B, $10 \mathrm{mg}$. daily, was injected into the pleural cavity for about 14 days. No complications occurred; the body temperature remained normal though corticosteroid treatment was stopped.

We saw her again in February and November 1967. She had no pulmonary symptoms and the E.S.R. was normal.

PATIENT 2 This 55-year-old housewife had chronic non-specific obstructive lung disease and bilateral apical inactive tuberculous lesions. In $1963 \mathrm{~A}$. fumigatus was cultured from the sputum and gradually the apical lesions began to show the typical appearance of an aspergillus mycetoma (Fig. 4).

In 1965 her symptoms became worse. The dyspnoea increased and she started producing large amounts of purulent, haemorrhagic sputum. The body temperature was febrile, between $38^{\circ}$ and $39^{\circ} \mathrm{C}$. In the serum precipitating antibodies to $A$. fumigatus were demonstrated. On skin-testing an immediate type I reaction (Gell and Coombs, 1963) was seen. With the exception of $A$. fumigatus in the sputum, no micro-organ- 


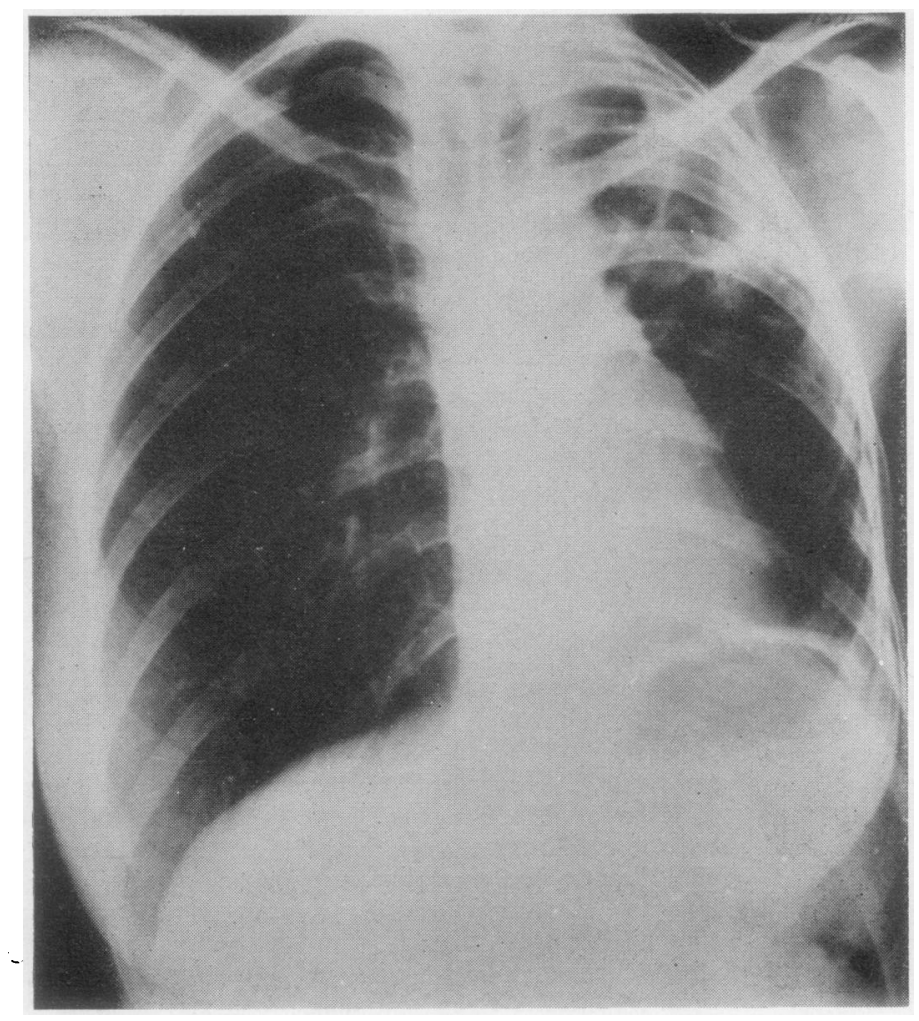

FIG. 1. Patient 1. Chest radiograph taken 응 during the first admission (April 1966) showing a large aspergillus mycetoma in $\bar{c}$ the left upper lobe.

FIG. 2. Patient 1. Results of immunoelectrophoresis (upper part) and Ouchterlony double diffusion test (lower part). Patient serum in upper trough in the immunoelectrophoresis and large well in the Ouchterlony. Aspergillus fumigatus extract in the small wells. The lower trough was not filled.

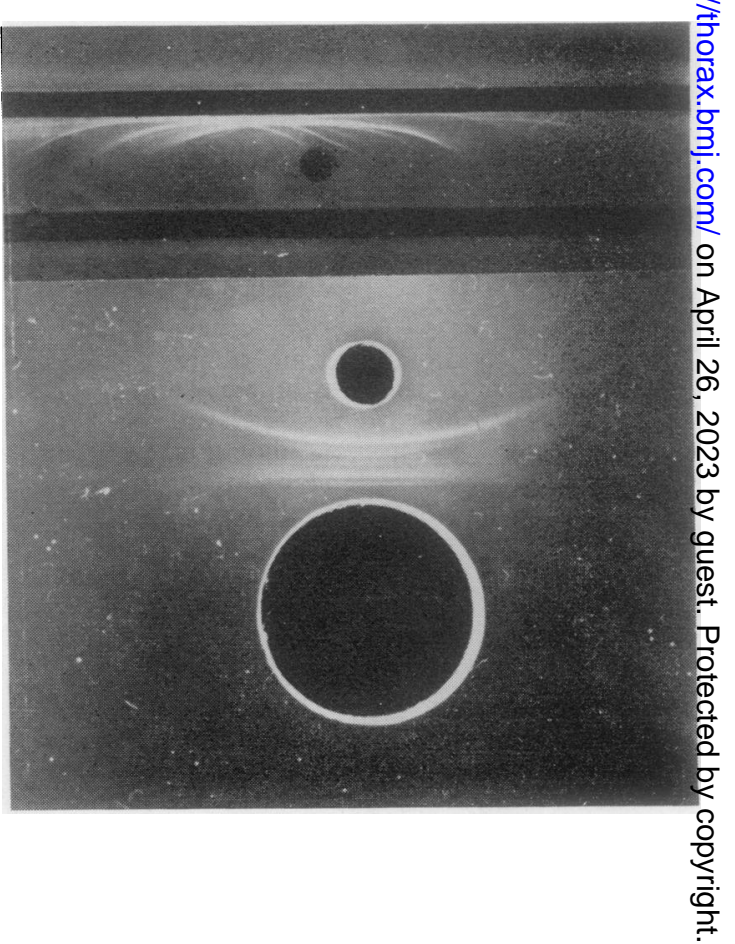




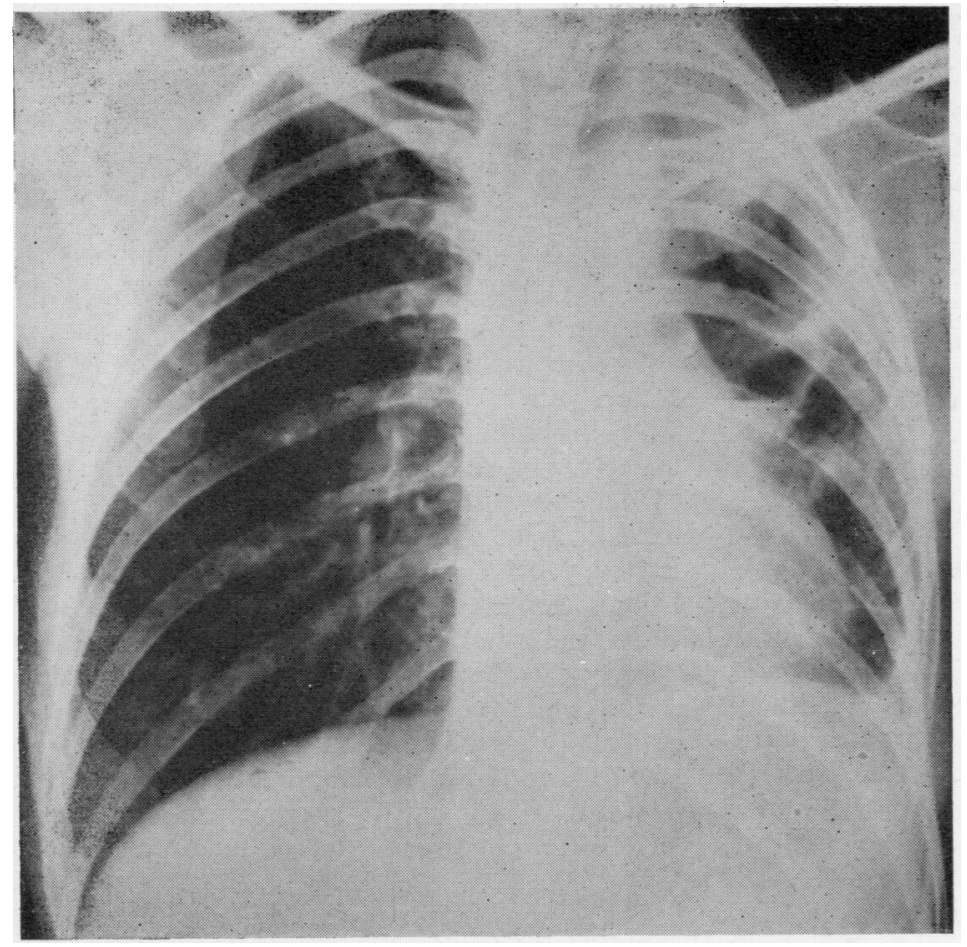

FIG. 3. Patient 1. Chest radiograph taken during the second admission (September 1966) showing an increase in size of the aspergillus mycetoma in the left upper lobe.

FIG. 4. Patient 2. Chest radiograph taken in 1963, showing aspergillus mycetoma with characteristic air-caps in right and left upper lobes.

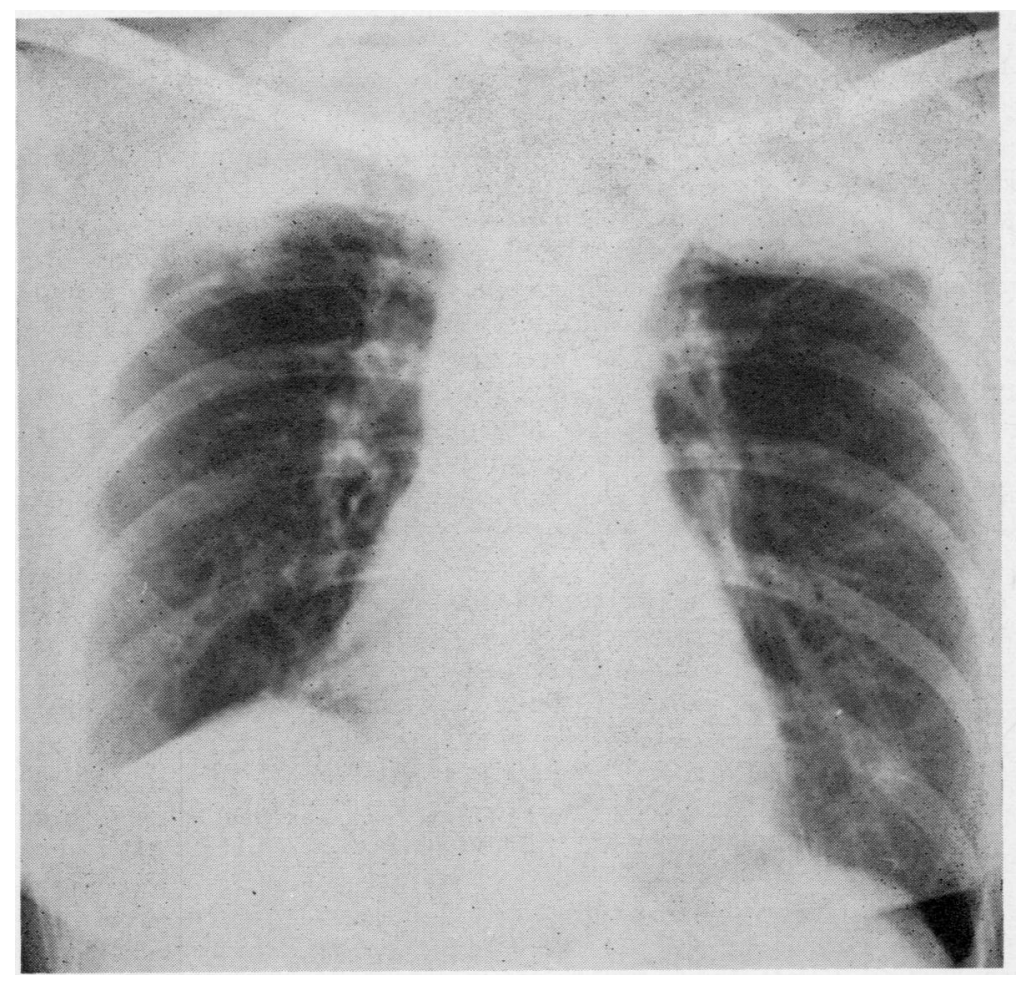


isms could be demonstrated in the blood, urine or sputum. Treatment with ampicillin and chloramphenicol did not result in any improvement.

Resection of the mycetoma was not possible because it was situated bilaterally and lung function was severely impaired. Again a course of amphotericin B had to be stopped because of acute renal failure. On administration of corticosteroids-prednisolone $25 \mathrm{mg}$. daily - the body temperature became normal and her symptoms improved. She was reasonably well for about two years on this regime, but finally died in March 1969 of respiratory failure.

\section{DISCUSSION}

In the two patients presented, apart from the presence of an aspergillus mycetoma, no other cause for the fever could be found. In the sera of both patients a high level of precipitins to A. fum:gatus could be demonstrated. On radiographic examination the picture was typical of an aspergillus mycetoma ; transient infiltrations as in allergic aspergillosis (Hinson et al., 1952 ; Pepys et al., 1959) were not seen. In the first patient the rise in temperature coincided with an increase in size of the aspergilloma, whereas the body temperature became normal when the aspergilloma was removed. In both patients administration of corticosteroids caused the temperature to drop to normal and an improvement of symptoms.

Stevens et al. (p. 11 in this issue) described a late febrile reaction in patients with aspergillus mycetoma on inhalation of $\boldsymbol{A}$. fumigatus extract. The fever in the present patients could have been caused by a similar probably allergic mechanism. In the opinion of Pepys et al. (1959), precipitating as well as reaginic antibodies might play a role in the causation of signs and symptoms in patients with allergic aspergillosis. The fever and transient infiltrations are attributed to a type III antigenantibody reaction in lung tissue surrounding the fungus, the latter being present intrabronchially (Scadding, 1967). A type I reaction might be involved in the causation of eosinophilia and bronchial obstruction.

If these types of reaction could exist independently in cases of hypersensitivity to $A$. fumigatus, theoretically, apart from the combined early and late reactions, two other patterns of reaction might be possible:

an early asthmatic reaction-'aspergillus asthma'-already described (Pepys et al., 1959);

a late reaction-not yet identified as a separate entity.

Probably the two patients with aspergilloma and fever represent examples of the latter type of reaction. However, it is difficult to explain why fever, a characteristic sign in patients with allergic $\overline{ }$ aspergillosis, is rare in patients with an aspergillus $\frac{\overline{7}}{\bar{N}}$ mycetoma. Several factors might be responsible, $\frac{\text { की }}{\overrightarrow{0}}$ such as the amount of precipitating antibody pre- $\mathbb{D}$ sent in the serum, a relation between the early is type I (Gell and Coombs, 1963) reaction and the $\vec{\circ}$ late febrile reaction in patients with allergic aspergillosis or the amount of antigen available for re- $\vec{\omega}$ action with circulating precipitins.

Precipitating antibodies are present more fre- $\overrightarrow{\vec{x}}$ quently and in higher concentration in the sera of patients with aspergilloma than in the sera of patients with allergic aspergillosis (Gernez-Rieux, $\vec{\bullet}$ Biguet, Voisin, Capron, and Tran van Ky, 1963 : Longbottom, Pepys, and Temple Clive, $1964: \stackrel{3}{-}$ Brönnestam and Hallberg, 1965).

A type I (Gell and Coombs, 1963) bronchial reaction preceding the late febrile reaction, as in patients with allergic aspergillosis (Pepys et al., ₹ 1959 ), is not a necessary condition for the occur- $\overrightarrow{0}$ rence of a late febrile reaction on inhalation of A. fumigatus extract (Stevens et al., p. 11 in this issue).

The amount of antigen available for reaction with circulating precipitins depends on the source of the antigen and its accessibility to the circulation.

The source of the antigen eliciting an attack in $\overline{\overrightarrow{0}}$ patients with allergic aspergillosis might be the 3 fungus present intrabronchially in varying amounts, depending on the degree of bronchial obstruction, but might also be environmental, as has been suggested by Henderson et al. (1968). In the patients presented here, the source of the $x$ antigen is probably not external because the fever persisted for several months in both of them even when the environment was changed. As was shown by Stevens $e t$ al., the late febrile reaction after one inhalation of an $A$. fumigatus extract lasted only 24 hours.

The foregoing arguments lead to the conclusion that the source of the antigen is the fungus present $\tilde{N}$ in the mycetoma, and that the occurrence of general symptoms and signs-previously not pre- N sent-depends only on a change, probably an $\omega$ increase, in the amount of antigenic material leaving the mycetoma, to react with circulating antibody.

Contact between antigen and antibody can $\stackrel{+}{+}$ theoretically occur $(a)$ across the wall between mycetoma and surrounding lung tissue; or $(b) \underset{\mathbb{D}}{\overparen{D}}$ across the alveolar membrane, when finely dis- $\frac{\stackrel{Q}{\mathbb{D}}}{\mathbb{Q}}$

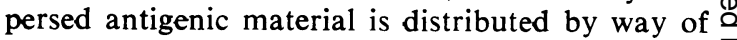
the bronchial tree to alveoli in normal lung tissue. 
In case $(a)$ the amount of antigenic material entering the circulation depends on the permeability of the wall for antigenic components of the fungus. Changes in this permeability may be caused by acute respiratory infections, causing an increase in blood flow in the surrounding lung tissue. Haemoptysis often occurs in patients with aspergillus mycetoma and bronchial infection. Haemoptysis, a characteristic symptom in patients with aspergillus mycetoma, should probably also be regarded as belonging to a type III reaction which, apart from fever, is characterized by vascular damage leading to oedema and haemorrhage (Cochrane, 1967).

In case $(b)$, the amount of antigen reacting with circulating antibody depends on the communication between bronchus and mycetoma and the fineness of the antigenic particles leaving the mycetoma. These particles might be mycelial fragments or spores. In the latter case, the relative rarity of general symptoms and signs in patients with aspergillus mycetoma would be explained by the rarity of sporulation (Orie, Vries, and Kikstra, 1960). Though highly speculative, this mechanism more or less agrees with the findings in patients with aspergillus mycetoma after experimental inhalation of $A$. fumigatus extract.

If most of the symptoms and signs in patients with aspergillus mycetoma could be attributed to a type III reaction, the administration of corticosteroids to some of these patients should be considered, especially in those cases with fever, malaise, or frequent and severe haemoptysis, in whom other methods of treatment have been without results, considered to be too dangerous, or have had to be stopped because of complications.

The usual treatment-resection-is often impossible because of the bilateral location of the aspergilloma or severely impaired lung function. The administration of amphotericin $B$ may also be considered. If given intravenously, the drug is extremely toxic (Utz, 1963 ; Utz, Bennett, Brandriss, Butler, and Hill, 1964) and only moderately active against $A$. fumigatus. However, good results have been reported after administration directly into the aspergilloma cavity by way of a transthoracic puncture (Krakowka, Chodkowska, Halweg, and Pawlicka, 1963 ; Brouet, Liot, Demange, and Nevot, 1964 ; Miguères, Paczuszynski, and Estève, 1965).

Corticosteroid treatment of patients with allergic aspergillosis is often successful. However, in these patients corticosteroids might assist in evacuating the fungus from the bronchial lumen by reducing oedema and inflammation of the bronchial mucosa. The effect of corticosteroid therapy would then not necessarily depend on a direct suppression of the type III reaction and the likelihood of undesirable effects-progression of fungus growth - would be decreased.

In patients with aspergilloma, removal of fungus as a result of corticosteroid treatment will probably not occur. Besides it has been shown that corticosteroids promote the growth of $A$. fumigatus in mice (Sidransky and Friedman, 1959 ; Hoër, 1964). Patients treated with high doses of corticosteroids for malignant haematological diseases (Torack, 1957) or as part of immunosuppressive therapy (Rifkind, Marchioro, Schneck, and Hill, 1967) show a high incidence of fungal infections, often with a fatal outcome. Although the dosages mentioned in these publications are much higher (equivalent to 60-100 mg. prednisolone daily) than those from which an effect might be expected in patients with allergic aspergillosis (20-30 mg. prednisolone daily), corticosteroids should only be used with the utmost caution in patients with aspergilloma.

In our opinion, there may be an indication for the administration of corticosteroids in some patients, since corticosteroids have been given to patients with an aspergillus mycetoma without having any unfavourable effect on the mycetoma.

\section{REFERENCES}

Annotation (1967). Lancet, 2, 1293.

Brönnestam, R., and Hallberg, T. (1965). Precipitins against an antigen extract of aspergillus fumigatus in patients with aspergillosis or other pulmonary diseases. Acta med. scand., 177, 385 .

Brouet, G., Liot, F., Demange, J., and Nevot, P. (1964). Traitement local de l'aspergillome pulmonaire par injections transpariétales d'Amphotéricine B. J. franc. Méd. Chir. thor., 18, 789.

Cochrane, C. G. (1967). The Arthus phenomenon-A mechanism of tissue damage. Arth. and Rheum., 10, 392.

Delikat, E., and Dyke, S. C. (1945). Acute pulmonary mycosis. Lancet, 2, 370.

Dieulafoy, G. (1920). Manuel de Pathologie Interne, Vol. 1, 6th ed., p. 430. Masson, Paris.

Gell, P. G. H., and Coombs, R. R. A., Ed. (1963). Clinical Aspects of Immunology, 1st ed. Blackwell, Oxford

Gernez-Rieux, C., Biguet, J., Voisin, C., Capron, A., and Tran van Ky, P. (1963). Diagnostic immunologique des aspergillomes bronchopulmonaires. Presse méd., 71, 1541.

Henderson, A. H., English, M. P., and Vecht, R. J. (1968). Pulmonary aspergillosis. Thorax, 23,513 .

Hertzog, A. J., Smith, T. S., and Goblin, M. (1949). Acute pulmonary aspergillosis. Report of a case. Pediatrics, 4, 331.

Hinson, K. F. W., Moon, A. J., and Plummer, N. S. (1952). Bronchopulmonary aspergillosis. Thorax, $7,317$.

Höer, P. W. (1964). Die Preumonomycosis aspergillina im Tierversuch und beim Menschen: Beitrag zur Pathogenese der Lungenmykosen. Ann. Univ. sarav. Med., 11, 363.

Krakowka, P., Chodkowska, S., Halweg, H., and Pawlicka, L. (1963). Treatment of pulmonary aspergilloma. Proc. int. symp. Med. Mycol., p. 249, Warszawa.

Longbottom, J. L., Pepys, J., and Temple Clive, F. (1964). Diagnostic precipitin tests in aspergillus pulmonary mycetoma. Lancet, 1 , 588 . 
Miguères, J., Paczuszynski, H., and Estève, R. (1965). Aspergillome pulmonaire en apparence prımitif, traité avec succès par injections trans-thoraciques d'Amphotéricine B. J. frans. Méd. Chir. thor., 19, 59.

Orie, N. G. M., Vries, G. A. de, and Kikstra, A. (1960). Growth of Aspergillus in human lung. Amer. Rev. resp. Dis., 82, 649.

Pepys, J., Riddell, R. W., Citron, K. M., Clayton, Y. M., and Short, E. I. (1959). Clinical and immunologic significance of Aspergillus fumigatus in the sputum. Ibid., 80, 167.

Rif kind, D., Marchioro, T. L., Schneck, S. A., and Hill, R. B. (1967). Systemic fungal infections complicating renal transplantation and immunosuppressive therapy. Amer. J. Med., 43, 28.

Scadding, J. G. (1967). The bronchi in allergic aspergillosis. Scand. $J$. resp. Dis., 48, 372.
Sidransky, H., and Friedman, L. (1959). The effect of cortisone and $\mathcal{W}$ antibiotic agents on experimental pulmonary aspergillosis. Amer. J. Path., 35, 169.

Stevens, E. A. M., Hilvering, C., and Orie, N. G. M. (1970). Inhalation experiments with extracts of Aspergillus fumigatus on patients $\bar{\omega}$ with allergic aspergillosis and aspergilloma. Thorax, 25, 11 .

Strelling, M. K., Rhaney, K., Simmons, D. A. R., and Thomson, J. $\mathbb{D}$ (1966). Fatal acute pulmonary aspergillosis in two children of
one family. Arch. Dis. Childh., 41, 34.

Torack, R. M. (1957). Fungus infections associated with antibiotic and steroid therapy. Amer. J. Med., 22, 872.

Utz, J. P. (1963). Chemotherapeutic agents for the systemic mycoses. New Engl. J. Med., 268, 938.

- Bennett, J. E., Brandriss, M. W., Butler, W. T., and Hill, G. J. (1964). Amphotericin-B toxicity. Combined clinical staff confer ence. Ann. intern. Med., 61, 334 . 